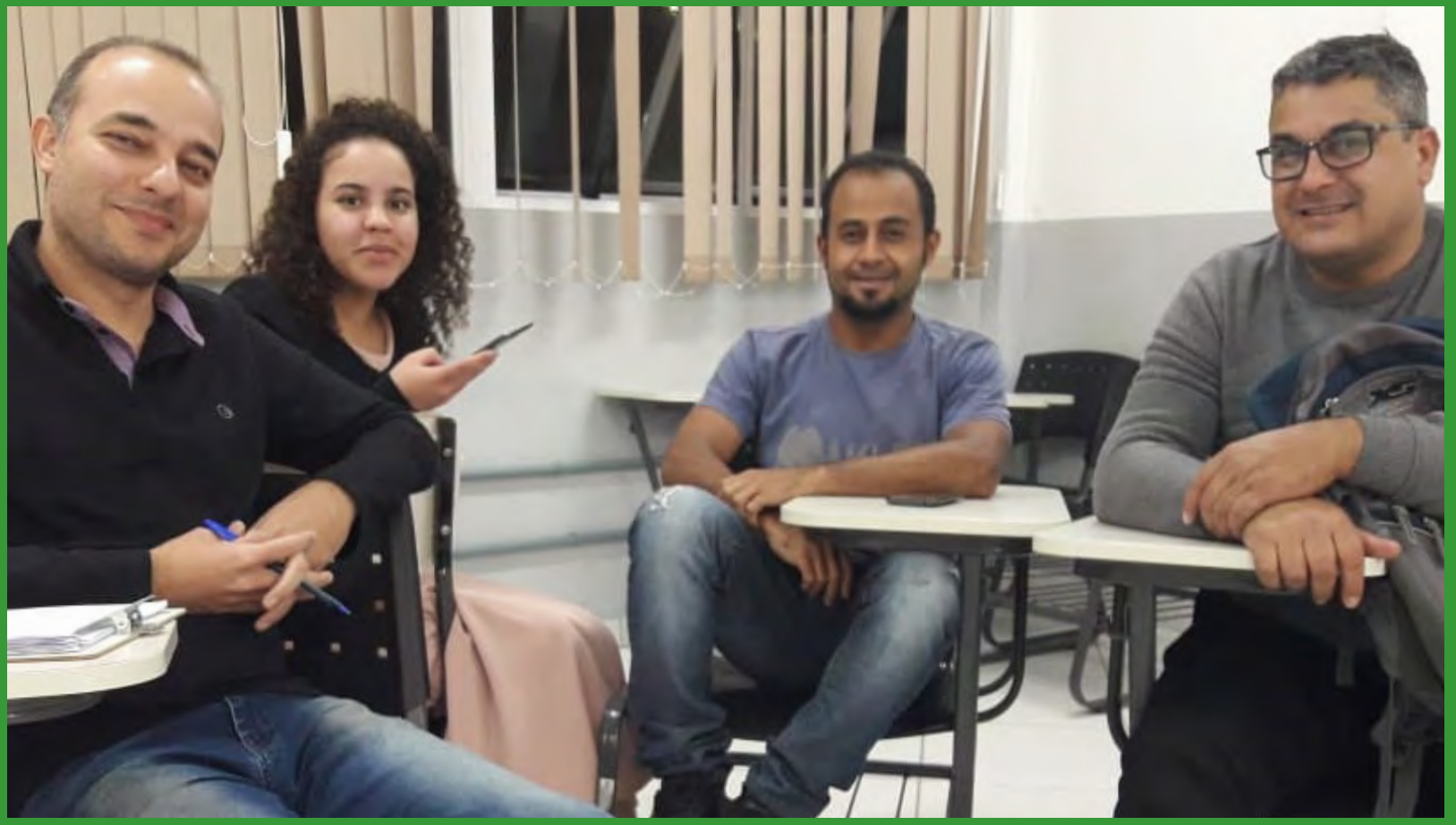

\title{
Diagnóstico da qualidade de processos, produtos e serviços de empresas da região de Gaspar-SC
}

Márcio Henrique Fronteli ${ }^{1}$ marcio.fronteli@ifsc.edu.br

Bárbara Silvana Sabino ${ }^{2}$ barbara.sabino@ifsc.edu.br

Vanessa Edy Dagnoni Mondini ${ }^{3}$ vanessa.dagnoni@ifsc.edu.br 
Este trabalho refere-se ao relato de experiência na curricularização da Extensão no Curso Superior de Tecnologia em Processos Gerenciais, em Gaspar-SC. Os estudantes tinham o objetivo de diagnosticar a qualidade de processos, produtos e serviços de empresas da cidade de Gaspar-SC e região. A proposta se dividiu entre diagnóstico e proposição de melhoria da qualidade. Os principais resultados foram a relação entre o IFSC e as empresas participantes, além de nove propostas de melhoria.

Palavras-chave: Gestão de Processos. Gestão da Qualidade. Proposta de Melhoria.

\section{ABSTRACT}

This work refers to the report of the experience in curricularisation of Extension in the Superior Course of Technology in Management Processes, in Gaspar-SC. The students had the objective of diagnosing the quality of processes, products and services of companies of the city of Gaspar-SC and region. The proposal was divided between diagnosis and proposition of quality improvement. The main results were the relationship between the IFSC and the participating companies, in addition to nine improvement proposals.

Keywords: Processes management. Quality management. Proposal for Improvement.

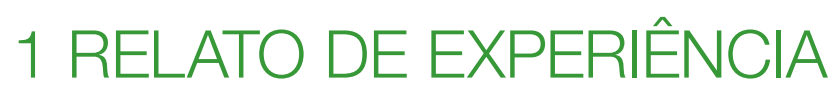

Este trabalho trata do relato da experiência na Curricularização da Extensão no Curso Superior de Tecnologia em Processos Gerenciais, em Gaspar-SC. No Câmpus Gaspar do IFSC, as práticas de extensão (ações, projetos e programas) sempre aconteceram, envolvendo a comunidade acadêmica e comunidade externa; porém, após a necessidade da curricularização da extensão, procurou-se a formalização e documentação dessas práticas. Isso possibilitou maior controle, facilitando os processos de contabilização de horas de extensão e atividades complementares para os discentes e incentivando a criação de novos projetos vinculados às bases tecnológicas dos cursos. Nesse sentido, o Projeto Pedagógico do Curso (PPC) Superior em Processos Gerenciais, aprovado pela resolução CEPE-IFSC 189/2017, foi readequado já contemplando a carga horária de extensão, indicadas nas unidades de ensino.

Oensino, pesquisa e extensãovoltados paraa compreensão e otimização de processos e do planejamento, visando melhoria contínua da qualidade, são ações indispensáveis nos cursos de gestão e negócios. A discussão referente à gestão da qualidade aliada à prática da visita in loco às empresas possibilita ao copo discente uma interação com os desafios e avanços reais presentes nas organizações, estabelecendo um espaço para que o aluno possa desenvolver significados práticos aos conteúdos disseminados em sala. Para além dessas possibilidades, a extensão proporciona uma aproximação entre o IFSC Gaspar e empresas da região.

De acordo com Paladini (2012), um roteiro prático para viabilizar a Gestão da Qualidade no processo envolve a implantação de atividades agrupadas em três etapas: 1) eliminação das perdas; 2) eliminação das causas das perdas; 3 ) otimização do processo. Uma melhoria da qualidade é o processo para produzir com níveis superiores e inéditos de execução, seja ela incremental (melhoria contínua) ou inovadora (melhoria radical) (CARPINETTI, 2012).

O Diagnóstico de Melhoria da Gestão da Qualidade IFSC/Gaspar foi um projeto de extensão estruturado mediante um conjunto de atividades teórico-práticas e que tem por objetivo promover um método de ensinoaprendizagem voltado para a atuação do discente em Arranjos Produtivos Locais (APLs) do Vale do Itajaí, contribuindo para o desenvolvimento de soluções de planejamento, controle e melhoria da qualidade para as empresas locais. 0 projeto contou com carga horária de 40 horas, sendo 20 horas presenciais, durante as aulas da unidade de ensino na 4 a fase do curso, e 20 horas para planejamento, visita às empresas, escrita do resumo expandido e confecção de um banner para apresentação dos resultados.

Para atingir os resultados desejados, as atividades do projeto foram realizadas em etapas, em forma de desafio, exigindo do discente participação efetiva e reflexão contínua dos conteúdos discutidos em sala de aula. Após a discussão de teorias e técnicas específicas, as equipes iniciaram o projeto realizando uma pesquisa sobre o perfil dos Arranjos Produtivos Locais (APLs) e empresas existentes na região do Vale do Itajaí. Posteriormente, escolheram uma empresa para realização do projeto, realizando depois as seguintes etapas:

Fase 1 - Diagnóstico atual de processos, produtos e operações realizadas pela empresa. Visita in loco, observação e entrevistas. Esta atividade serviu para auxiliar na compreensão do "status quo", ou seja, como a organização realiza suas atividades, processos, planejamento e controle da qualidade.

Fase 2 -Proposta de melhoria da qualidade. Atividades realizadas em sala de aula. Elaboração de proposta de melhoria da qualidade visando redução de custos da não-qualidade, otimização de recursos e processos. 
Fase 3 - Realizar a escrita de um resumo expandido; atividades realizadas em sala de aula.

Fase 4 - Produzir um banner. Atividades realizadas em sala de aula.

Durante a execução das atividades as equipes foram orientadas para a realização de cada atividade nos encontros presenciais semanais, em sala de aula (Figura 1), e por e-mail. 0 desempenho individual dos alunos foi avaliado através do cumprimento de prazo e atividades solicitadas, além da qualidade dos textos (resumo expandido e banner) desenvolvidos. Já a avaliação da equipe foi feita mediante a participação nas visitas na indústria para a coleta de dados, entrega dos relatórios solicitados e a elaboração/apresentação da proposta, sendo observado o cumprimento das regras estabelecidas pelo professor.

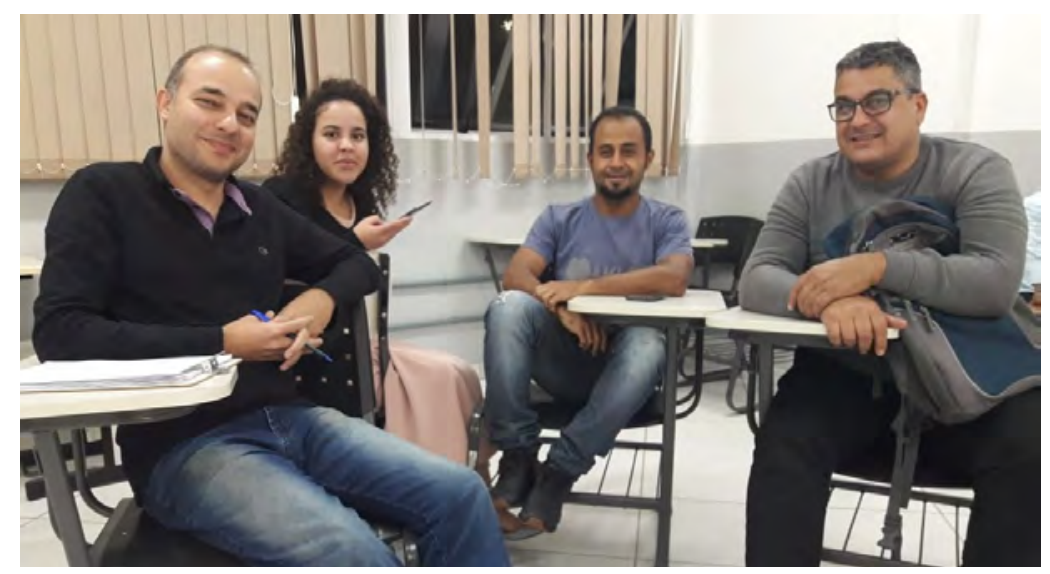

Figura 1: Atividades realizadas em sala de aula

Fonte: Dados do projeto.

0 público participante deste projeto foi estimado em 200 pessoas, sendo da comunidade interna: 50 estudantes da 4a fase do curso nos períodos 2017/2-2018-1, como pode ser visto no convite para a comunidade externa de 2018 na (Figura 2); 70 estudantes de cursos técnicos e superiores que participaram como ouvintes das apresentações dos resultados (banner); comunidade externa: 80 pessoas envolvidas nas empresas que receberam as equipes; e avaliadores externos dos trabalhos, indicados pela Prefeitura de Gaspar, Associação Comercial e Industrial, sindicatos e empresas estudadas, entre outras.

Para a obtenção do engajamento e motivação dos participantes, buscou-se apresentar os benefícios do projeto. Para a comunidade interna, o trabalho serviu de grande incentivo para elaboração de projeto de melhoria da qualidade, praticar a gestão em equipe e apresentação para as empresas e entidades seus resultados.

Para a comunidade externa, foram feitos convites para avaliar os projetos, conhecer o IFSC, seus alunos e o curso de Processos Gerenciais. As empresas estudadas sempre foram abordadas e retratadas como organizações abertas para melhoria, forjando uma imagem positiva para o projeto e para a apresentação dos estudantes, fator que ajudou a participação das empresas.

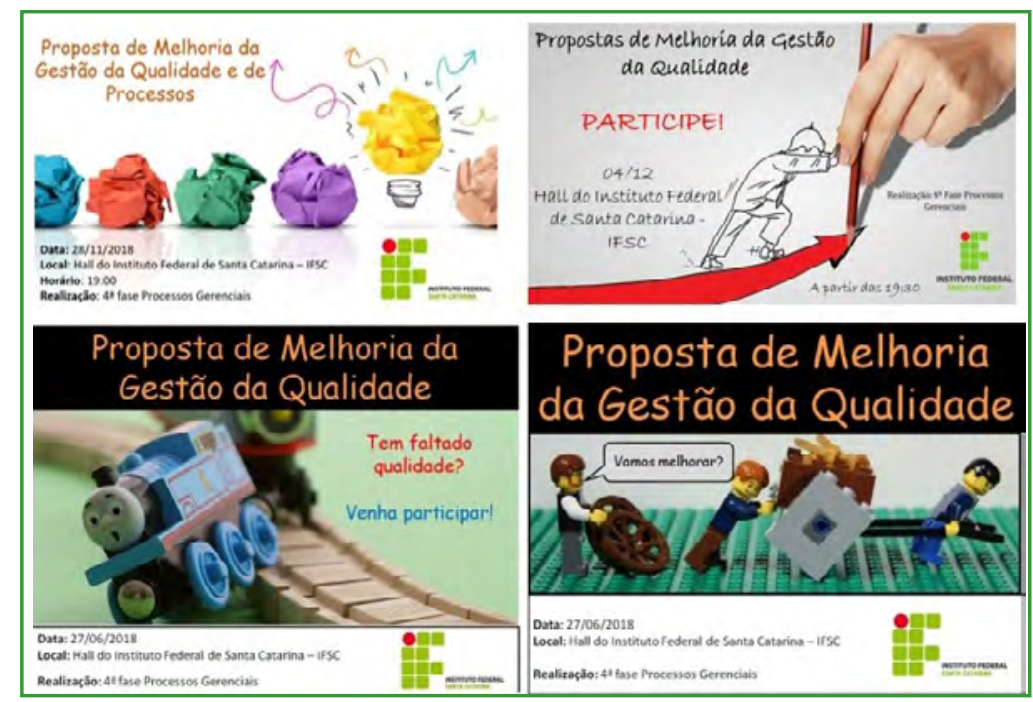

Figura 2: Convites das apresentações

Fonte: Dados do projeto. 
Justificou-se esta proposta, uma vez que os estudantes tiveram acesso à realidade de empresas da região, sua rotina de trabalho, histórico, sistema produtivo, gestão da qualidade de seus processos e produtos, demonstrando que os conceitos aprendidos em sala de aula são aplicados na prática pelas empresas.

Os principais resultados apresentados foram: desenvolvimento do senso crítico por parte dos alunos participantes do projeto quanto ao planejamento, controle e melhoria da qualidade e suas complexidades; estabelecimento de umarelação entreo IFSCGaspar eempresas daregião direcionada para o desenvolvimento de tecnologias organizacionais; produção de conhecimento técnico referente à Gestão da Qualidade das empresas que estará disponibilizado nos formatos de texto.

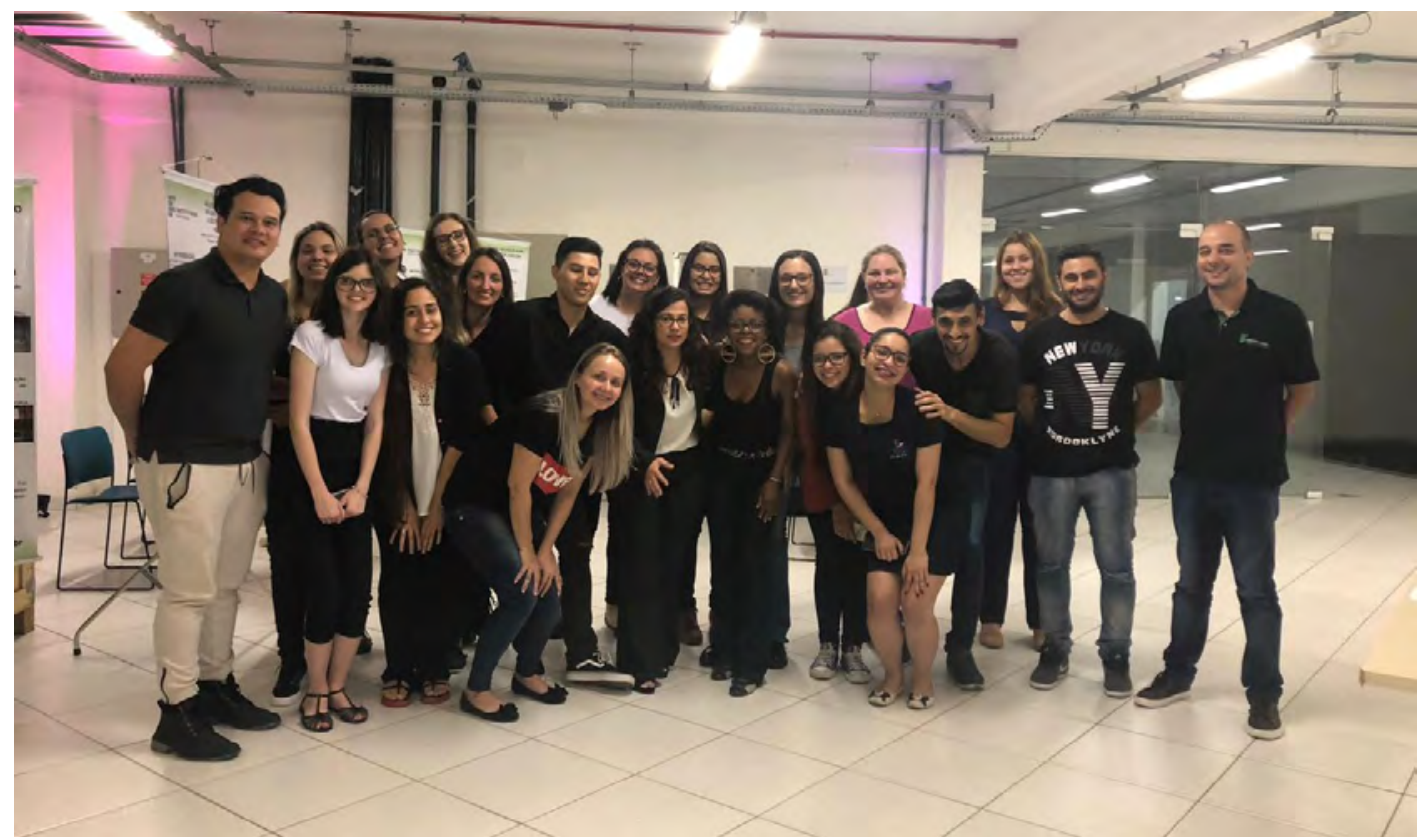

Figura 3: Apresentações dos resultados.

Fonte: Dados do projeto.

Uma das equipes buscou analisar o processo de comunicação com Pessoas com Deficiência (PCD), pois a empresa analisada tem dois funcionários surdos e apresenta dificuldades na comunicação com eles. Esta equipe elaborou uma proposta visando a inclusão dos funcionários e melhoria no processo de comunicação interna. A apresentação do banner contou com a participação de um intérprete de libras e envolveu alunos do curso FIC de libras do Câmpus Gaspar.

Neste sentido, obteve-se o encontro dos alunos com o universo profissional, proporcionando aos participantes uma formação mais ampla, atividade de grande relevância para os alunos do curso superior, uma vez que nela é possível observar o ambiente real de uma empresa em pleno funcionamento, além de ser possível verificar sua dinâmica, organização e todos os fatores teóricos implícitos nela.

Por fim, as principais barreiras encontradas para a curricularização da extensão neste projeto foram as dificuldades encontradas pelos estudantes em acessar o ambiente das empresas, conseguir informações para fazer o levantamento e diagnóstico e finalizar as propostas.

\section{REFERÊNCIAS}

CARPINETTI, L. C. R. Gestão da qualidade: conceitos e técnicas. São Paulo: Atlas, 2012.

CARVALHO, M.; PALADINI. Gestão da qualidade: teoria e casos. Rio de Janeiro: Elsevier Brasil, 2013.

IFSC. Projeto Político Pedagógico do Curso Superior de Tecnologia em Processos Gerenciais. Disponível em: http://www.ifsc.edu.br/curso-aberto/-/asset_publisher/nvqSsFwoxoh1/content/id/657601?p_r_p_564233524 categoryld=657579. Acesso em: 25 jul. 2018. 